\title{
Pensamento Computacional e Programação Scratch: uma revisão de literatura do SBIE
}

\author{
Luísa S. Ferreira ${ }^{1}$, Sylvana Karla S. L. Santos ${ }^{1}$, Cristiane Jorge L. Bonfim ${ }^{1}$ \\ ${ }^{1}$ Instituto Federal de Brasília - Campus Brasília \\ \{luisasouzalinda90, sylkarla\}@gmail.com, cristiane.bonfim@ifb.edu.br
}

\begin{abstract}
The purpose of this article is to present a survey of the works that relate computational thinking and the Scratch platform in the context of teaching programming to high school students. To this end, a literature review was carried out with a focus on studies related to practical experiences in the context of basic education, mainly in elementary education. The search considered the works published in the SBIE in the period from 2001 to 2019.

Resumo. O objetivo deste artigo é apresentar um levantamento dos trabalhos que relacionam pensamento computacional e a plataforma Scratch no contexto do ensino de programação para estudantes da educação básica. Para tanto, foi realizada uma revisão de literatura com o foco em estudos relacionados às experiências práticas no contexto da educação básica, principalmente no ensino fundamental. A busca considerou os trabalhos publicados no SBIE no periodo de 2001 a 2019.
\end{abstract}

\section{Introdução}

O uso de ferramentas computacionais tem possibilitado a construção de atividades dinâmicas para promover maior interesse dos estudantes, aumentar a interação e ressignificar práticas docentes em vários níveis de ensino da educação básica [Pereira e Franco 2018].

A resolução de problemas pode ser abordada a partir do pensamento computacional (PC), que é uma metodologia com múltiplas características e requisitos que viabilizam a relação entre conteúdos acadêmicos diversos [Almeida, Nunes e Almeida 2017]. Trata-se de um processo que envolve a "resolução de problemas, a capacidade de projetar sistemas e a compreensão do comportamento humano recorrendo aos conceitos fundamentais da Ciência da Computação" [Wing 2006].

No cenário do ensino remoto, ferramentas computacionais mais visuais têm sido adotadas para aumentar o engajamento, diminuir o distanciamento físico e promover uma maior aprendizagem. O Scratch ${ }^{1}$ é uma linguagem de programação com características essencialmente visuais. Criada em 2007 pelo MIT - Massachusetts Institute of Technology, o Scratch utiliza blocos que permitem a criação de programas de computador sem a necessidade de aquisição da sintaxe de uma linguagem de programação para os iniciantes [Rodriguez et al. 2015].

No Instituto Federal de Brasília (IFB) encontra-se em andamento uma pesquisa de iniciação científica (PIBIC-EM) cujo foco é desenvolver vivências de curta duração alinhadas com o currículo escolar e voltadas ao pensamento computacional para

\footnotetext{
${ }^{1}$ Scratch. Disponível em: https://scratch.mit.edu/
} 
estudantes do ensino fundamental de uma escola pública do Distrito Federal, por meio da plataforma Scratch.

$\mathrm{Na}$ fase atual da pesquisa, foi elaborado um levantamento dos trabalhos publicados no Simpósio Brasileiro de Informática na Educação (SBIE), organizado pela Sociedade Brasileira de Computação (SBC) e que é referência na área da Informática na Educação. O levantamento foi realizado a partir dos Anais do evento, que acontece desde 1990, no intuito de encontrar experiências já desenvolvidas por outros pesquisadores e que sirvam como insumo para prosseguimento da pesquisa.

Assim, este trabalho tem o objetivo de identificar e sintetizar as pesquisas já realizadas e divulgadas no evento, relacionadas ao pensamento computacional e à Plataforma Scratch.

\section{Metodologia da Revisão de Literatura}

O levantamento dos dados da pesquisa seguiu a metodologia de trabalho denominada Revisão de Literatura, com o objetivo de identificar e analisar pesquisas publicadas nas edições do Simpósio Brasileiro de Informática na Educação (SBIE), de 2001 a 2019, relacionadas ao tema do PIBIC-EM. Foram escolhidos os termos "pensamento computacional" and "scratch". A busca foi realizada na página do evento $<\underline{\text { https://br- }}$ ie.org/pub/index.php/sbie/index $>$.

A partir da consulta na página, foram obtidos nove resultados, conforme quadro 1, destacando ano de publicação, título e autores:

Quadro 1: Publicações no SBIE de 2001 a 2019.

\begin{tabular}{|c|c|c|c|}
\hline Id & Ano & Título & Autores \\
\hline 1 & 2017 & $\begin{array}{l}\text { Um Método para o Desenvolvimento de } \\
\text { Software com Crianças Utilizando o Ambiente } \\
\text { Scratch }\end{array}$ & $\begin{array}{l}\text { Stephanie da Silva Ribeiro, Amanda } \\
\text { Meincke Melo. }\end{array}$ \\
\hline 2 & 2017 & $\begin{array}{l}\text { O Pensamento Computacional por meio da } \\
\text { Robótica no Ensino Básico - Uma Revisão } \\
\text { Sistemática }\end{array}$ & $\begin{array}{l}\text { Christiano Avila, Simone Cavalheiro, } \\
\text { Adriana Bordini, Monica Marques. }\end{array}$ \\
\hline 3 & 2017 & $\begin{array}{l}\text { Metodologias de avaliação do Pensamento } \\
\text { Computacional: uma revisão sistemática }\end{array}$ & $\begin{array}{l}\text { Christiano Avila, Simone Cavalheiro, } \\
\text { Adriana Bordini, Monica Marques, } \\
\text { Maicon Cardoso, Gustavo Feijó }\end{array}$ \\
\hline 4 & 2017 & $\begin{array}{l}\text { A Última Árvore: exercitando o Pensamento } \\
\text { Computacional por meio de um jogo } \\
\text { educacional baseado em Gramática de Grafos }\end{array}$ & $\begin{array}{l}\text { Braz Junior, Simone Cavalheiro, } \\
\text { Luciana Foss }\end{array}$ \\
\hline 5 & 2017 & $\begin{array}{l}\text { Uma Proposta para o Desenvolvimento do } \\
\text { Pensamento Computacional Integrado ao } \\
\text { Ensino de Matemática }\end{array}$ & $\begin{array}{l}\text { Monica Marques, Simone Cavalheiro, } \\
\text { Luciana Foss, Christiano Avila, } \\
\text { Adriana Bordini. }\end{array}$ \\
\hline 6 & 2018 & $\begin{array}{l}\text { Uma análise cognitiva entre a emergência de } \\
\text { padrões em narrativas infantis e elementos do } \\
\text { pensamento computacional }\end{array}$ & $\begin{array}{l}\text { Fernanda Pires, José Carlos Duarte, } \\
\text { Larissa Pessoa, Karla Susiane Pereira, } \\
\text { Rafaela Ferreira, Rosiane de Freitas. }\end{array}$ \\
\hline 7 & 2018 & Análise de Discurso e de Conteúdo de uma & Taiser Barros, Eliseo Reategui, Ricardo \\
\hline
\end{tabular}




\begin{tabular}{|c|l|l|l|}
\hline & & $\begin{array}{l}\text { Formação em Pensamento Computacional } \\
\text { para Professores }\end{array}$ & Radaelli, Adriano Teixeira. \\
\hline 8 & 2018 & $\begin{array}{l}\text { Programando para criar objetos de } \\
\text { aprendizagem digitais de Ondulatória }\end{array}$ & $\begin{array}{l}\text { Fabrizio Franzoia, Fernanda Gabriela } \\
\text { de Sousa Pires, Karolayne Batista } \\
\text { Teixeira, Polianny Lima }\end{array}$ \\
\hline 9 & 2019 & $\begin{array}{l}\text { JogLog - Jogos de Raciocínio Lógico para } \\
\text { Alunos do Ensino Fundamental: Um Estudo } \\
\text { de Caso Utilizando Gamificação e Pensamento } \\
\text { Computacional }\end{array}$ & Odair Souza \\
\hline
\end{tabular}

Fonte: elaborado pelas autoras [19 mar. 2021].

A maioria dos trabalhos foi publicada em 2017, totalizando cinco trabalhos. Em menor quantidade, três publicações foram divulgadas em 2018 e apenas uma em 2019. Como critérios de inclusão, foram elencados: (1) possibilidade de metodologia para ser adaptada com os alunos do ensino fundamental; (2) objetivo principal desenvolver e exercitar o PC; (3) existência de um método utilizado; (4) a junção do PC a algum conteúdo, jogo ou projeto. Os critérios de exclusão foram: (1) não apresentar resultados; (2) não usar o Scratch como plataforma principal; (3) o foco principal não é os estudantes, associadas aos diversos níveis de ensino e, principalmente, ao ensino fundamental.

\section{Resultados}

Após leitura do resumo dos nove trabalhos encontrados, publicados entre 2017 e 2019, foram elencados sete, pois atendem aos critérios anteriormente indicados. Estes últimos foram lidos na sua totalidade para se certificar do contexto e da validação. Os trabalhos 3 e 7 não foram considerados relevantes para a pesquisa, pois não usam o scratch ou não têm relação com práticas de PC (3) e não possuem foco no ensino (7). Os demais estudos, considerados expressivos para o objetivo deste trabalho, têm como base o Scratch para o desenvolvimento do PC (1, 4, 6, 8 e 9), permitem a adaptação da metodologia empregada $(1,2$ e 9$)$ e propõem uma aplicação relacionada a alguma disciplina do currículo escolar $(5$ e 8$)$.

\section{Considerações}

A partir das referências alcançadas por meio do levantamento de literature do SBIE, espera-se que o projeto possa aproveitar as experiências para ser melhorado e, dessa forma, servidor como base para o planejamento das atividades para obter um resultado satisfatório junto aos alunos. A partir da leitura dos trabalhos, a bolsista do projeto obteve embasamento teórico para conhecer experiências exitosas e associar às práticas da plataforma Scratch para que, com o auxílio do pensamento computacional, consiga capacitar os estudantes e auxilia-los a resolver problemas de um forma diferente.

Os trabalhos identificados na busca foram publicados nas edições do evento de 2017 a 2019, o que pode indicar uma importância ao tema dada mais recentemente pelos pesquisadores. A escolha pelo formato completo (10 páginas) e a autoria múltipla pode denotar que as investigações são executadas por grupos de pesquisa com foco no aumento da produção científica. Em suma, todo o conhecimento, dicas e métodos adquiridos neste levantamento será usado para o aprimoramento da pesquisa que está sendo realizada com os alunos do ensino fundamental de uma escola pública do Distrito Federal. 


\section{Referências}

Almeida, J. V. R., Nunes, M. V. C. B., Almeida, F. M. A. (2017) Desenvolvimento de jogos com uso de Pensamento Computacional e Aprendizagem Baseada em Projetos. In: Encontro Nacional de Computação dos Institutos Federais. 4., pp. 252-255.

Avila, C.; Cavalheiro, S., Bordini, A.; Marques, M. (2017) O Pensamento Computacional por meio da Robótica no Ensino Básico - Uma Revisão Sistemática. In: Simpósio Brasileiro de Informática na Educação, p. 82-91.

Avila, C.; Cavalheiro, S., Bordini, A.; Marques, M.; Cardoso, M.; Feijó, G. (2017) Metodologias de Avaliação do Pensamento Computacional: uma revisão sistemática. In: Simpósio Brasileiro de Informática na Educação, p. 113-122.

Barros, T., Reategui, E.; Radaelli, R.; Teixeira. (2018) Análise de Discurso e de Conteúdo de uma Formacão em Pensamento Computacional para Professores. In: Simpósio Brasileiro de Informática na Educação, p. 1733-1737.

Franzoia, F.; Pires, F. G. S.; Teixeira, K. B.; Lima, P. (2018) Programando para criar objetos de aprendizagem digitais de Ondulatória. In: Simpósio Brasileiro de Informática na Educação, p. 1063-1072.

Marques, M.; Cavalheiro, S.; Avila, C.; Bordini, A. (2017) Uma Proposta para o Desenvolvimento do Pensamento Computacional Integrado ao Ensino de Matemática. In: Simpósio Brasileiro de Informática na Educação, p. 314-323.

Pereira, A. C., Franco, M. E. (2018) Desenvolvendo o pensamento computacional no ensino fundamental com Arduino e Scratch. In: Encontro Nacional de Computação dos Institutos Federais, 5.

Pires, F. G. S.; Duarte, J. C.; Pessoa, L. S.; Pereira, K. S. S.; Melo, R.; Freitas, R. (2018) Uma análise cognitiva entre a emergência de padrões em narrativas infantis e elementos do pensamento computacional. In: Simpósio Brasileiro de Informática na Educação, p. 1193-2004.

Ribeiro, S.; Melo, A. (2017) Um Método para o Desenvolvimento de Software com Crianças Utilizando o Ambiente Scratch. In: Simpósio Brasileiro de Informática na Educação, p. 1027-1036.

Rodriguez, C. L., Zem-Lopes, A. M., Marques, L., Isotani, S. (2015) Pensamento Computacional: transformando ideias em jogos digitais usando o Scratch. In: Workshop Informática na Escola. pp. 62-71.

Silva Júnior, B. A.; Cavalheiro, S. A. C.; Foss, L. (2017) A Última Árvore: exercitando o Pensamento Computacional por meio de um jogo educacional baseado em Gramática de Grafos. In: Simpósio Brasileiro de Informática na Educação, p. 735-744.

Souza, O. M. (2019) JogLog - Jogos de Raciocínio Lógico para Alunos do Ensino Fundamental: Um Estudo de Caso Utilizando Gamificação e Pensamento Computacional. In: Simpósio Brasileiro de Informática na Educação, p. 1022-1031.

Wing, M. J. (2006). Computational Thinking. Communications of the ACM. v. 49, n. 3. http://www.cs.cmu.edu/ CompThink/papers/Wing06.pdf Acesso em: 10 mar. 2021. 